\title{
Parents' Views of their Children's online Learning in The UAE Context during the COVID-19 Pandemic
}

\author{
Chaya Heba* and Salem Sultan
}

Ph.D. Candidate at the British University in Dubai, UAE

Ph.D. at University of Birmingham, UK

DOI: $10.36348 /$ jaep.2020.v04i10.004

| Received: 07.10.2020 | Accepted: 21.10.2020 | Published: 29.10 .2020

*Corresponding author: Heba Chaya

\section{Abstract}

The purpose of this study was to investigate parents' views regarding online learning during the COVID-19 pandemic in the UAE context. A concurrent mixed method design was utilized to collect both quantitative and qualitative data from a sample of 122 parents who live in the UAE. Primary data was collected with a questionnaire which was developed by the researcher based on a literature review. Results indicated consistency between the quantitative and qualitative findings. Parents' satisfaction of online learning in the UAE context was equally divided between being satisfied, not satisfied, and neither satisfied nor dissatisfied. Parents' suggestions to improve online learning were revealed. The need for more interactive live sessions between teachers and students and more communication between the schools and parents were the parents' most repeated suggestions for better online learning quality and experience. The findings of this study can be used by educational policymakers and stakeholders to enhance the online learning experience in the UAE context.

Keywords: Online learning, COVID-19, UAE educational context, parents' views.

Copyright (C) 2020 The Author(s): This is an open-access article distributed under the terms of the Creative Commons Attribution 4.0 International License (CC BY-NC 4.0) which permits unrestricted use, distribution, and reproduction in any medium for non-commercial use provided the original author and source are credited.

\section{ABBREVIATION}

ADEK: Abu Dhabi Department for Education and

Knowledge

BUiD: British University in Dubai

COVID-19: Novel Coronavirus. A virus that causes respiratory infections.

KHDA: Knowledge and Human Development

Authority

OECD: Organisation for Economic Co-operation and

Development

PBL: Project-based learning

UAE: United Arab Emirates

WHO: World Health Organization

\section{INTRODUCTION}

The new coronavirus (COVID-19) has been described as the "worst nightmare", due to its high degree of transmissibility and mortality rate, by Dr. Anthony Fauci [1], a public health expert and renowned immunologist who advises the US government on COVID-19. Since its outbreak in January 2020, the virus has devastated the world with tragic human losses and unprecedented economic turmoil as lockdowns were imposed varyingly across the world. As of July 2020, the virus has already caused over half a million deaths worldwide [2], with global economic losses estimated at $\$ 3.5$ trillion [3]. As a result of the lockdown, temporary school closures have been recorded in 216 countries [2], rendering more than $90 \%$ of the global student population (around 1.2 billion children) across $\mathrm{K}-12$ to higher education having to adopt online or remote learning methods, as they are being kept out of their classrooms during the pandemic.

While many features of physical, face-to-face learning are expected to resume over the next 12 months, it is assumed that this pandemic may prove to be a watershed moment in online and remote learning, as well as a critical moment for educators to identify the most successful methods for online teaching. At the same time, traditional educational institutes that are facing interruptions and challenges during this pandemic may be forced to implement significant changes out of necessity, with many possibly ending up transitioning to online learning. Indeed, the online education market has witnessed significant growth and is projected to reach $\$ 350$ billion by 2025 [4].

Online learning along with the coronavirus disease pandemic has brought new challenges to families across the globe [5], especially for parents who play the major, critical and evident roles of cheerleaders and instructors in supporting their children's well-being 
and maintaining their undisrupted learning within a safe environment during the COVID-19 outbreak [6]. No one knows when this situation will come to an end, which is why schools across the United Arab Emirates (UAE) are planning to continue providing online learning as the academic year resumes in September, possibly for the entire academic year. For instance, educational stakeholders in the UAE noted that they anticipated blended teaching delivery in the first term of the 2020-21 academic year as they wait for an official decision from the government [7]. To support parents, educators and practitioners in this time of uncertainty, ADEK, KHDA, UNICEF, WHO, and many other international organizations published hundreds of guidelines and manual handbooks for educational stakeholders, teachers, and parents. These materials provide stakeholders with insights into educating students and best practices during this time of uncertainty. Moreover, they have helped stakeholders to draw lessons from this exceptional crisis and to build long-term sustained resilience in education systems [8].

While the issue of online education has drawn academic interest, very few studies were conducted to study the issue from the parents' views, with limited studies exploring parents' views and experiences on online learning, especially in the UAE. For example, in one of the latest published articles [9] the author tackled the parents' perceptions of e-learning in Abu Dhabi schools. Thus, in this paper, which is, to the best of our knowledge, the first study that addresses and investigates the parents' views of online learning during the COVID-19 pandemic in the UAE context, we will contribute to the ongoing professional discussion to establish an overall understanding of the parents' opinions of online learning in the UAE context.

\section{Problem Statement}

On March 22, 2020, the UAE government announced the suspension of all schools across the emirates to prevent the spread of COVID-19 [6]. In order to guarantee that learning continued during the temporary closure, the government instructed that online learning should start in all schools. Under this UAE-wide direction, the Ministry of Education has been working closely with all private schools to ensure that they are prepared and equipped with the right resources to implement online learning for all students in the UAE context [6].

Within the challenging COVID-19 outbreak, parents' responsibilities have expanded as they have had to manage their children learning from home along with ensuring their well-being and online safety at all times. After three months of online learning, it has become evident that few parents were able to manage their children's distance learning while many others were struggling in different ways. Parents play a vital role in their children's success. Thus, during the distance-learning period, they were encouraged to provide structure, support, and guidance at home, which proved to have a significant positive impact on children's performance [6]. Therefore, the Ministry of Education and educational stakeholders were constantly in contact with parents to incite them to take an active interest in online learning and provide the right learning environment for their children at home.

Numerous studies and handbooks regarding the online learning topic are available $[10,11]$ in addition to studies on the teachers' perceptions and attitudes towards online learning. The latter studies demonstrate findings that consistently reveal different perceptions to e-learning between teachers as some of them prefer the face-to-face or traditional teaching method while others highly recommend blended and online learning [12, 13] and studies on student motivation in online learning $[14,15]$. However, few studies focused on parents' views of online learning. For instance, Abdallah [9] conducted a study in the UAE and revealed that parents in Abu Dhabi were not satisfied, neither familiar with e-learning and one of the recommendations was for the educational stakeholders and researchers was to conduct more studies on how to improve the quality of student's learning and engagement in online learning [9]. Therefore, the researchers find it significant to investigate the parents' views of online learning in the UAE context, especially during the COVID-19 pandemic, as parents were extremely involved in online learning during this critical period of time; this investigation should be conducted in order to pinpoint gaps and deficits in online learning. These gaps will be considered as opportunities for educational stakeholders to take them into consideration and therefore to improve the online educational platforms in order to enhance the students' online learning experiences in the UAE context, as well as the parents' experiences in online learning, especially if the school closures will remain for a longer period of time.

\section{Purpose and Aim of the Study}

The researcher's main purpose of this research study was to investigate parents' views regarding online learning in the UAE context during the COVID-19 pandemic. The main question of this study is "What are the parents' views of online learning in the UAE context during the COVID-19 pandemic"?

\section{Rationale of the Study}

Based on the reviewed literature, the authors find it significant to conduct the present and unique study as findings will give an overall insight of the parents' views of online learning in the UAE. It will also provide an enhanced comprehension of their position of e-learning, in regards to features such as the safety of their children in online learning, the use of resources, the load and the quality of the delivered material, and the collaboration between the participants involved. Moreover, this study will highlight the 
parents' suggestions on how the school should change in order to enhance the students' and the parents' online learning experience. In fact, the parents' views, insights, and suggestions for the improvement of online learning are essential during this period of time, as parents are highly engaged in online learning as their children's educational coaches and assistants at home. Additionally, this study will participate in the establishment of knowledge and guidelines that can be used by online learning designers and educational policymakers and planners in order to enhance online learning and to meet the students' and parents' needs, especially in the UAE context. Lastly, it is imperative for the UAE policy makers to identify parents' views regarding online schooling as imposed by the COVID19 pandemic, as well as the results of such essential research inquiry, as the $\mathrm{UAE}$ and the Arabic region strive to provide a world class education to their children.

\section{LITERATURE REVIEW Online Learning}

There are fluctuating attitudes towards elearning. Few researchers believe that online learning has a similar level of effectiveness as the conventional teaching method and that there is no noticeable discrepancy in students' academic performance between those who pursue their education through internet-based-modes and those who go to the face to face or the conventional way in their education [11]. Yet, numerous reviews came up with a wide positive reflection towards the online learning by demonstrating that the online learning method has several levels of efficiency based on the results of the students' academic achievement and success in online learning environments while other studies reported that this channel of delivery has instead an opposing effect on the students' academic achievement [16].

For instance, the availability and the accessibility to educational resources in all times by students from different and separated regions; the independent learning, the flexibility of the online learner in the online learning environment, the communication between the students and teachers who cannot be consulted locally and, the use of technology are factors that improve the achievement of autonomous and responsible students in online learning [17]. However, online learning is not the best delivery channel for all situations as the learners in online learning environments might face isolation, social development lapse, language difficulties, technology issues and, safety and well-being concerns besides enduring the non-cooperative tutors and the lack of constructive and individualized feedback that can demotivate and impact them in a negative way [18].

\section{Parent's Involvement in their Children's Education}

Being involved in their children's education is not a new issue for parents. For instance, parents had been involved in nursery schools since the beginning of the twentieth century in the United States of America where the stay at home mothers were welcomed to serve as paraprofessionals or assistants in the classrooms. Later on, in 1975 parent involvement was commanded by the Education of All Handicapped Children Act and similarly by the Individuals with Disabilities Educational Improvement Act in 2004 [19]. Furthermore, the Goals 2000 project came to mandate the intensification of parent-school partnership in all states in America [20] to sustain the academic work of youngsters at home and to share the educationaldecision making with parents especially the ones of the disadvantaged kids [21]. Finally, the No Child Left behind (NCLB) legislation in 2002 allowed the parents to have access to their children academic progress in school [22] and obliged the schools to provide the parents comprehensible description of the curricula and to offer them meetings and training to improve their involvement in decision- making in schools [23].

\section{Parental Involvement in their Children's learning in the UAE}

In the UAE, parental involvement in their children's education level is quite mixed. For instance, numerous factors such as the cultural background, the parents' educational level, the roles of helpers at home, the magnitude of the school- parent's relationship play a huge role in identifying the level of parental involvement observed in the UAE. Research in the UAE context revealed that parents are always confused as to what is to be expected of them concerning their responsibility and their input in their children's education [24]. Moreover, they often question to what extent they can influence their children positively in their educational environment especially that they believe that by choosing the most expensive private school for their children, they are offering them the best education along with a higher social status in the community [25].

Parents in the UAE are distant from their children's education. In fact, fifty-one percent of students in Dubai at the age of fifteen are taking private lessons with private tutors in at least one subject. This rate is significantly higher than the international OECD [24] average of twenty-eight percent. For instance, parents in UAE seek to private tutoring when they are not able to provide the necessary academic support to the children, when they don't have enough time to contribute to their children's education and when they want to prove that they are caring parents by offering their children the maximum opportunity [26].

Some schools in the UAE have undertaken initiatives to incite parental involvement in their children's education through communication, collaboration, meetings, and assemblies. Though, parental engagement in their children's educational lives is still very shy. This is relatively due to the 
misunderstanding of parents of their main role as partners in their children's learning rather than focusing on daily issues like transportation and textbooks [27]. For instance, parental involvement in schools is still limited to social events' organization and other activities that are far from teaching and learning in the classroom [24]. Subsequently, and due to the positive significant effect of the parental involvement in their children's lives, parents' involvement in their children's education in the UAE is highly recommended, especially the involvement of the fathers as most of the schools in the UAE have a deficit of male teachers. Therefore, fathers' involvement within the families who live in the UAE is highly suggested to reflect and instill the effective male role model in their children's lives.

\section{METHODOLOGY}

A concurrent mixed method design is used for the present study to collect both quantitative and qualitative data from a sample of 122 parents who live in the UAE context and who were involved in online learning during the COVID-19 pandemic. Primary data was collected with a questionnaire that was developed by the researcher based on the literature review. The concurrent design is advocated when the researcher need to validate one form of data with another form or to transform data for comparison [28]. Both quantitative and qualitative data were collected from the same sample using a questionnaire consisting of structured (closed-ended) and unstructured (open-ended) questions. While the structured questions permit the researcher to effortlessly assemble and summarize data on required and actual characteristics of the participants and their views of online learning during the COVID19 pandemic, the unstructured questions allow the participants to enter extensive comments about their overall views of online learning and their suggestions to schools to change in order to enhance their experiences as parents and their children's experiences in online learning. Moreover, the usage of a concurrent mixed method design allows the researcher to compare findings from the quantitative and qualitative data in order to reach a broader comprehensive, accurate, and truthful understanding of the parents' views regarding online learning.

\section{Population and Sample}

The population in this study consists of all the students' parents, mothers and fathers, who live in the UAE and who were engaged with their children in online learning during the COVID-19 pandemic. A total of 122 complete questionnaires were collected by the researcher within three days from a random sample with the participation of 84 mothers and 38 fathers who meet the mentioned criteria. The total number of participants in this study is convenient as most statisticians recommend a minimum sample size of 100 in order to acquire meaningful results [29]. The questionnaire, which was developed by the researcher based on the literature review, was used as a tool for this study and was randomly sent by the researcher to the parents through the WhatsApp application. Furthermore, the researcher asked the participants to spread the questionnaire to all parents who meet the required criteria. In fact, this digital approach to send the questionnaire was chosen as it is inexpensive and it allows the researcher to acquire access to parents that might be difficult to reach in person, especially during the COVID-19 pandemic. Moreover, it allows the participants to take sufficient time to fill the questionnaire and to give thoughtful answers to the questions [26]. Prior to that, the questionnaire was piloted by five parents in order to confirm the validity and the appropriateness of the instrument. For instance, Fraenkel and Wallen [26] argued that pretesting the questionnaire reveals ambiguities, weakly worded questions, questions that are not comprehended, and doubtful choices. Pretesting can also indicate if the instructions to the participants are clear and welldefined. Upon completion, results were collected digitally through the SurveyMonkey application.

\section{Questionnaire's Description}

The questionnaire was developed by the researcher based on literature reviews of online learning and consists of eight parts with closed-ended questions and the last part with three open-ended questions. The first part of the questionnaire elicits parental demographic data that consists of five categorical-type questions, such as gender, age, education level, family size, and parental working status. The second part consists of four Likert-type questions (e.g., 1= strongly disagree; $5=$ strongly agree) that concern the parents' perceptions of online learning. The third part consists of four Likert-type questions that concern the parent-child relationships in online learning. The fourth part consists of three Likert-type questions that concern the parentteacher/ administration relationships in online learning. The fifth part consists of seven Likert-type questions that concern the child-teacher relationships in online learning. The sixth part consists of four questions that concern the delivered online content. The seventh part consists of three questions that concern child safety in online learning. The eighth part consists of three questions that concern children's well-being in online learning. The last part of the questionnaire consists of three unstructured or open-ended questions that provide the opportunity for the parents to enter allencompassing comments about their overall views regarding online learning and their suggestions to schools to change in order to enhance their experiences as parents and their children's experiences in online learning.

\section{DATA ANALYSIS AND RESULTS Quantitative Analysis}

The SurveyMonkey was used to analyze data. The study collected data from 122 participants within three days, from 13-6-2020 until 16-6-2020 with a $100 \%$ completion rate. In the quantitative section, 
descriptive statistics (frequency and percentage distributions) are used to represent the data. In fact, by using descriptive statistics the researcher is able to gather mixed information and to measure the variables related to a specific phenomenon. Statistics related to parents' demographic characteristics were analysed first (gender, age, education level, family size, and working status). For instance, most of the parents who participated in the questionnaire were identified as female, emphasizing a total participation of 84 mothers $(68.85 \%)$ whereas $38(31.15 \%)$ were identified as male. In terms of age, parent age range was normally distributed within five categories, for instance, parents of the first two categories, under 34 years were represented the least $(7.38 \%)$, while the third category was the largest and it accentuated parents within the age range 35-44 with 78 (63.93\%) participants. Moreover, normally distributed results demonstrated that 53 (43.4\%) parents hold a bachelor's degree, equally to parents who hold a master's degree, while only 13 $(10.66 \%)$ hold a doctoral degree. Regarding family size, normally distributed results showed that the largest sample of $62(50.82 \%)$ participants have two children. Finally, data on working status revealed that most of the participants are working parents $(89,72.95 \%)$.

Parent satisfaction with e-learning during the COVID-19 pandemic in the UAE context was investigated with the help of a five Likert-type question. Equally distributed results show that 42 (34.43\%) parents were satisfied of online learning, 41 (33.61\%) were neither satisfied or dissatisfied, and 39 (31.97\%) were dissatisfied (Fig. 6).

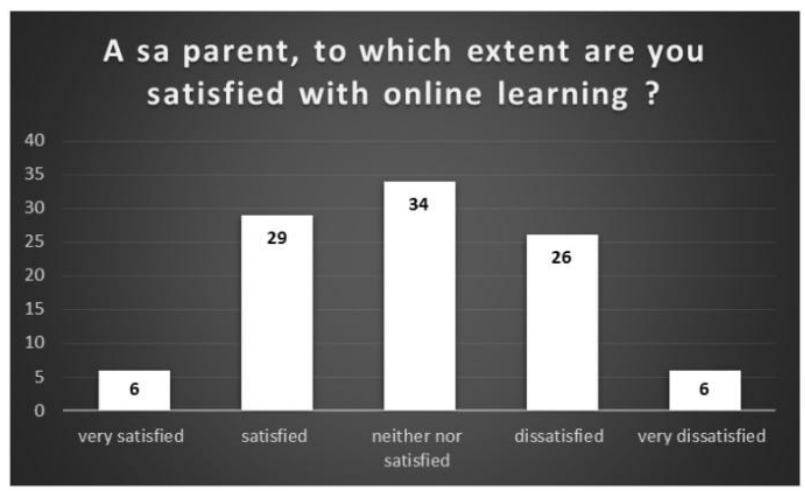

Fig-6: Parents' Satisfaction of Online Learning during the COVID-19 Pandemic

The second part of the questionnaire intended to investigate the parents' perception of online learning during the COVID-19 pandemic in the UAE context with four Likert-type questions. Results showed that 42 $(34.43 \%)$ parents agreed, whereas 36 (29.51\%) disagreed that they have positive attitudes towards online learning. These results are aligned with the parents' answers on how well they were coping with their children's learning from home. For instance, 47 $(38.52 \%)$ parents agreed that they are coping well with their children's learning from home while 36 (29.51\%) disagreed. The last two questions in this section examined how adequate the parents' educational and technological backgrounds were to support their children's online learning. The answers came consistent in the two questions, as most of the parents $(43 ; 37)$ strongly agreed that they have adequate educational and technological backgrounds to support their children's online learning, while the largest number $(51,58)$ agreed and a smaller number $(19,15)$ neither agreed nor disagreed.

The third part of the questionnaire envisioned to reconnoiter types of opportunities offered by online learning to parents. Results showed that the majority of participants agreed that online learning offered them an opportunity to build a good relationship with their children $(46,37.70 \%)$, gave them a deeper insight into their children's weaknesses and strengths $(54,44.26 \%)$ and offered them the opportunity to address their children's educational needs $(55,45.08 \%)$ though fewer parents agreed that it gave them a deeper insight to identify their children's most appropriate domain for the future $(38,29 \%)$ where the majority of participants neither agreed nor disagreed $(53,43.44 \%)$.

In the fourth section of the questionnaire, the researcher intended to explore how supportive the school was during the COVID-19 pandemic. As Fig. 9 shows, most participants agreed that the administration kept them updated and engaged with regular newsletters about the school performance in online learning; the IT department was supportive regarding technical issues; and that teachers were cooperative and offered guidance when needed $(72,59.02 \% ; 51,41.80 \% ; 68,55.74 \%)$ whereas the least number of participants strongly disagreed $(0,0 \% ; 2,1.64 \% ; 0,0 \%)$.

The fifth section collected information about the teachers' attitudes regarding online learning. The results suggested that most parents agreed that their children's teachers had positive attitudes towards online leaning $(71 ; 58.20 \%)$; did their best in online leaning $(63,51.64 \%)$, were flexible and cooperative (69, $56.56 \%)$; gave their children personalized, valid and constructive feedback $(46,37.70 \%)$; used positive reinforcement and virtual rewards to motivate their children (43, 35.25\%); and lastly used many instructional techniques with concrete examples to enhance their children's learning $(52,42.62 \%)$, while fewer participants strongly agreed $(22.13 \%$; $22.95 \%$; $23.77 \% ; 18.85 \% ; 18.85 \% ; 17.21 \%$, respectively.

In the sixth section, data was collected to explore the parents' views of the delivered online material. The results suggested that the highest percentage of participants agreed that the online material was delivered in a clear way $(56.56 \%)$ and it was well planned $(56.56 \%)$, while $40.16 \%$ agreed that it was reliable and sufficient to meet their children's educational needs. Additionally, $49.18 \%$ agreed that the 
online classroom was easy to navigate with clear objectives and goals. Fewer participants neither agreed nor disagreed $(17.21 \% ; 14.75 \% ; 27.05 \% ; 24.59 \%$, respectively).

The last two sections of the questionnaire intended to explore the parents' views of their children's safety and well-being in online learning. Results suggested that a majority of participants agreed that their children are safe in online learning $(58.20 \%)$ while around $11 \%$ disagreed. Additionally, 57.38\% agreed that they were regularly checking the information and the material being exchanged between their children and their peers while $13.93 \%$ disagreed. Furthermore, the results fluctuated between strongly agreed $(45.90 \%)$ and agreed $(31.15 \%)$ regarding the concern of the parents of their children being exposed to long screen time during the online learning. Regarding the children's well-being in online learning, the participants' answers fluctuated respectively between agreed and neither agreed or disagreed. In fact, $35.25 \%$ agreed that the online classes curricula enclosed stories and activities that helped their children practice mindfulness and self-reflection in order to maintain their well-being during the COVID-19 pandemic while $33.61 \%$ neither agreed or disagreed. Furthermore, $51.64 \%$ and $46.72 \%$, respectively, agreed that teachers' teaching and learning approaches were packed with care, concern and compassion and that their children had the opportunity to socialize and to support their peers in online learning compared to $31.15 \%$ and $26.23 \%$ who neither agreed nor disagreed.

The structured questions of the questionnaire came to an end by asking the parents about their overall experience where results suggested that online learning met the expectations of $50.82 \%$ of the participants; exceeded the expectations of $11.84 \%$ of the parents while $37.7 \%$ of the participants responded that it was below their expectations (Fig. 14).

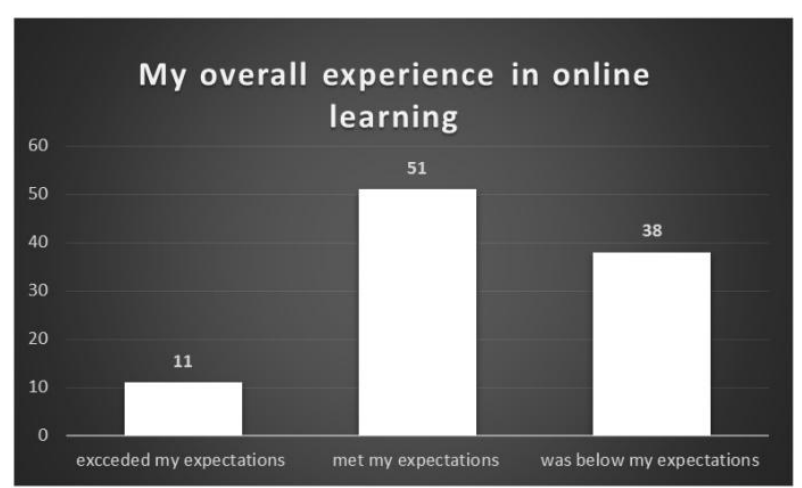

Fig-14: Parents' Overall Experience in Online Learning

\section{Further Analysis}

The comparison function in the Survey Monkey was to explore the relationships between the variables. For instance, results suggested that parents, who are female or mothers along with participants who have two children, who do work, who hold a master's degree, who have kids in the elementary school, and whose age range fluctuates between 35 and 44 years old, tend to be satisfied with online learning during the COVID-19 pandemic in the UAE context. Consequently, this same group of participants who were satisfied with online learning indicated that the online learning met their expectations. In fact, analysis showed that mothers, along with participants who hold a master's degree, who have two children, who do work, whose kids are in the elementary school, and whose age range varies between 35 and 44 denoted that the online learning met their expectation. Therefore, the researcher concluded that the data is reliable and consistent.

\section{Qualitative Analysis}

A content analysis as a qualitative descriptive approach is utilized in analysing the participants' answers in the last three open-ended questions which intended to ask the parents of what the school should change in order to enhance the parents' and the students' experiences in online learning, as well as their overall views of the online learning during the COVID19 pandemic in the UAE context. This approach is appropriate for researchers who desire to use a reasonably low level of interpretation. Content analysis is a systematic coding and categorizing approach used for studying textual information to establish trends and patterns of words used, their frequency, and their relationships. Moreover, by using content analysis, a researcher is able to analyze data qualitatively and to quantify the data [30]. This approach is largely based on the factist perspective which considers data to be relatively precise and truthful indexes of reality [31]. The process of data analysis in content analysis according to Elo and Kyngäs [32] consists of preparing the data (immersing in the data and acquiring sense); organizing the data (generating categories and subcategories under higher order headings) and, reporting the data (reporting the emerged results/final product). Themes which are considered to be the final product of data analysis are defined as coherent integrations of the disparate pieces of data that constitute the findings [33] as they capture something important about data in relation to the research question and represent meanings within the data set [34].

Question 1- Based on your online experience during the COVID-19 pandemic, what do you suggest the school should change in order to support you as a parent in online learning?

Table 1(See Appendix) provides a sample of responses allocated by parents and organized by the researcher with the major coding categories.

Six groups were identified vis-à-vis question number 1. Examination of these groups reveals that school support is mandatory for parents to enhance their experiences during the COVID-19 pandemic. For instance, parents suggested that schools have to be more supportive and professional by offering more webinars 
or live sessions to engage them, support them and guide them in online learning. This claim was repeatedly made by working parents who claimed that they need more support to be able to cope with their duties and the online learning. Furthermore, regular communication between the school and the parents was a commonly assigned code according to the parents' responses. In fact, half of the participants have asked for clear communication on the content objectives, curriculum and how they can support their children at home. Likewise, the most obvious pattern appears for the code Teachers-parents communication where patterns indicate that parents generally ask the teachers for "Feedback on their children's learning"; "Sessions between the teachers and the parents where they can brief the parents about what is expected of them in elearning"; "A weekly short webinar about 30 minutes to explain to parents the focus of the subject units of the week". Furthermore, considering the burdened class content and the performance evaluation was also a common code assigned by the parents' responses. For instance, "To reduce the amount of work and assignments, taking into consideration working parents and their backgrounds"; "Reconsidering the whole curriculum"; "System should meet current scenario and not load the children with unnecessary information and subjects" and; "Providing clarity of assessment" are answers which were frequently repeated by the parents. Additionally, few parents asked to reconsider the school tuition fees as the online learning shifted the teaching burden on them. On the other hand, relatively few responses mirrored the desire of parents to reconsider the re-opening of the schools and the end of online leaning.

Question 2- Based on your online experience during the COVID-19 pandemic, what do you suggest the school should change in order to support your child in online learning?

Table 2 (See Appendix) provides a sample of responses allocated by parents and organized by the researcher with the major coding categories.

In question number 2, the researcher inspected patterns in parents' answers regarding what schools should change in order to enhance the student experience in online learning during the COVID-19 pandemic in the UAE context. The analysis of parents' responses revealed that nearly all of the parents referred to frequent and daily interactive live sessions between teachers and students through Google meet, Zoom meetings and Microsoft Teams videos in order "to engage the children and maintain their interest". Likewise, a furthermost obvious pattern appears for the code consider the students well-being where patterns indicate that offering the children opportunities to socialize with their peers, their teachers and their counsellors, as well as "Focusing more on specialists' subjects and adding mandatory subjects to help them mentally to cope with the lock down, like meditation and mindfulness" are compulsory in online learning to "ensure that students feel supported in online learning". Furthermore, re-considering the burdened class content and design as well as the assessment procedure was also a communal code assigned by the parents' responses. For instance, and in order to improve the student achievement in online learning, parents suggested that the school has to "Reduce the number of tasks", "Provide better planned lessons", and "Understand the difference between online schooling and classroom teaching and adapt accordingly". These responses were in addition to "Ensuring that students aren't falling behind by providing more communication and clarity of assessment", with "More individualised assignments based on different levels or skills/abilities". Additionally, engaging students with PBL and group works along with considering a better reward system seems to be a mutual code allocated by the parents' responses. For instance, parents claimed that "It would be beneficial to engage the child in group projects to maintain their interest" and "More virtual rewards and encouragement" are highly encouraged to motivate students in online learning. Lastly, a numerous number of parents stated that teachers' support is highly advised to encourage students in online learning. In fact, "Teachers need to be more present and supportive"; "More interaction between teachers and students during the classes to improve their attention and concentration" are a sample of parents' answers regarding this code. On the other hand, few parents asked to reconsider the length of the online learning time as they believe that their kids are exposed to too much screen time.

Question 3 - May you describe your view of Online Learning in the UAE context during the COVID-19 pandemic? Please provide some examples.

Table 3 provides a sample of responses allocated by parents and organized by the researcher with the major coding categories.

Three groups were identified vis-à-vis question number 3 where parents' overall views were divided nearly in an equal way between parents who had negative experiences, parents who had positive experiences and parents who were neutral or did not answer. In fact almost a third of the participants agreed that they had a positive experience in online learning during the COVID-19 pandemic in the UAE context, where they stated that they had "an excellent experience", "The school handled it in a very professional way since the beginning", "Serious, adequate, ambitious, yet appropriate as an emergency trial", and "It was well managed and everything was made available". In contrast, another third of the total participants had a negative experience where they claimed that the online learning in the UAE context was "Inconsistent from one school to another" and "Immature, unhealthy for the child, lonely, passive, not 
sustainable and, very disappointing". These views along with their proportion were consistent with the quantitative analysis results where the percentage of satisfied parents of online learning (35\%) was almost the same as the percentage of the dissatisfied parents (32\%) while the remaining percentage were neutral regarding the online learning.

Table-1: Coding categories and sample responses to open-ended question \# 3

\begin{tabular}{|c|c|}
\hline $\begin{array}{l}\text { Coding } \\
\text { Categories }\end{array}$ & Sample of parents' responses \\
\hline $\begin{array}{l}\text { Negative } \\
\text { experience }\end{array}$ & $\begin{array}{l}\text { It's inconsistent from one school to another. } \\
\text { New experience. Immature } \\
\text { Unhealthy for the child } \\
\text { Lonely and passive ... praying our children will get to go back to a normal fun learning } \\
\text { experience in September!!! } \\
\text { Not sustainable in the long run } \\
\text { It is a mess in progress } \\
\text { It was very disappointing } \\
\text { There is still a lot of progress to be made }\end{array}$ \\
\hline $\begin{array}{l}\text { Positive } \\
\text { experience }\end{array}$ & $\begin{array}{l}\text { Fairly managed given the short time to prepare it! } \\
\text { Online learning was good in order for the kids not to miss their school year but unfortunately } \\
\text { there was a lot of pressure on the parents, especially the ones working or having more than one } \\
\text { child } \\
\text { It was the best solution } \\
\text { Overall, it was a great plan since the pandemic was a total surprise } \\
\text { The school handled it in a very professional way since the beginning } \\
\text { I had a good and positive experience } \\
\text { Compared to what our relatives \& friends face in other countries, I find that UAE is leading } \\
\text { I had an excellent experience } \\
\text { Adequate, ambitious, yet appropriate as an emergency trial } \\
\text { It was very serious } \\
\text { It's good in a time of crisis but it adds a lot of burden to the parents } \\
\text { It was well managed. Whether it was, the apps or connectivity or resources, everything was } \\
\text { made available }\end{array}$ \\
\hline $\begin{array}{l}\text { Neutral } \\
\text { experience }\end{array}$ & $\begin{array}{l}\text { N/A } \\
\text { It was okay }\end{array}$ \\
\hline
\end{tabular}

\section{DISCUSSION}

Online learning has made education more freely available through abolishing the word impossible in the study process [35]. In fact, online learning nurtured the feature of making learning available in all cases, especially during crises, as demonstrated during the COVID-19 pandemic in 2020. In this study, 122 parents living in the UAE context were surveyed randomly to investigate their views of online learning during the COVID-19 pandemic. The current survey study used a mixed methods approach to collect both quantitative and qualitative data with a concurrent design in order to confirm and cross-validate findings within the study. Findings were very interesting and showed similarities as well as contrasts in the parents' responses and views.

For instance, working parents were more satisfied with online leaning than non-working parents. The reason behind this, as per the researcher, could be that non-working parents were more familiar, as part of their job, with online learning than working parents were. In other words, they were more able to examine and to assess the content, the teachers' attitudes, the assessment procedure, the homework, the teachers' feedback, the teacher-student conversations, the tutorials and their children's physical and emotional statuses. Therefore, their negative feedback was based on their ability to obtain a deeper overall insight of all the elements of the online learning. Moreover, mothers were more satisfied than fathers with the online learning. These results came out of the researcher's expectations and further research could be done to further investigate the reasons behind them.

Additionally, it is inferred from the consistent quantitative and qualitative data that overall parents' satisfaction of online learning in the UAE context is equally divided between being satisfied, not satisfied, and neither satisfied nor dissatisfied. Many variables could be behind these results. For instance, the satisfaction of online learning is affected by its easiness and convenience [36]. In other words, parents show their satisfaction with online learning if the process appears to be easy and convenient for their children. Hence, although most of the parents agreed in their qualitative responses that the online learning was the only convenient solution for their children to pursue their studies during the pandemic especially in the UAE, which is perceived as a growing country that 
embraces technological trends and teaching practices as a pioneer [9]. However, their responses were divergent of how easy the process was. The extent of easiness is related to many variables. This included, the parents' educational and technological backgrounds which are necessary to cope with online learning, the parents' support from the school and the teachers, as well as the parents' views of the content quality, weight, clearness and, effectiveness along with the parents' worries of the length of time spent in online learning, and finally the students' physical and emotional health. These are all factors that can affect the parents' perception of the easiness of online learning.

Quantitative statistics showed that more than $75 \%$ of the participants have the required educational and technological backgrounds to be able to cope with their children's learning in an online format and more than $80 \%$ were satisfied with the teacher and the school support, while only $62 \%$ were satisfied with the quality, fairness, and weight of the delivered online material. These results were inconsistent with the study of Abdallah [9] who investigated parents' perceptions of online learning in Abu Dhabi and who claimed that parents in Abu Dhabi were less satisfied with the quality of e-learning in terms of content and the teaching procedure. In fact, Abdallah stated in her study that parents in Abu Dhabi were not satisfied with the teachers' teaching procedures and computer competencies used in online learning while this study confirmed that $73 \%$ of the parents were satisfied with the teachers' instructional techniques used in online learning during the COVID- 19 pandemic. Furthermore, findings regarding the children's well-being and their ability to socialize with their peers in online learning showed the satisfaction of $50 \%$ and $80 \%$ of the parents, respectively. These results were in stark contrast to Abdallah's findings which revealed that parents in Abu Dhabi have low satisfaction regarding the children's personal development and well-being in online learning. Furthermore, Kong's [37] research claimed that a number of parents in Hong Kong were concerned about students' weakening interpersonal skills due to overreliance on digital devices, as they could be used as a substitution for oral communication. However, $77 \%$ of the total parents agreed that they are worried about their children being exposed to too much screen time during online learning, which positively confirms Kong's [37] findings which elucidate that parents in Hong Kong are worried about the negative effects of elearning devices on their children's health, specifically on their eyesight.

Moreover, parents' perceptions of the elearning process are not only determined by its easiness, convenience, or utility but also on the basis of its overall implication on performance. In other words, parents will be satisfied with the online learning process if it will enhance and improve their children's performance [27]. For instance, this study revealed that
$87 \%$ of parents agreed that online learning during the COVID-19 pandemic gave them a deeper insight into their children's weaknesses and strengths in different subjects and the opportunity to address them. However, $47 \%$ of the participants disagreed that the teachers are providing their children with personalised, valid and constructive feedback in order to enhance their learning in online learning.

Lastly, although online learning is an idyllic learning mechanism for students of all age groups and backgrounds [38] and despite the high proportion of students convinced with the e-learning system in the UAE context [9], various and fluctuating answers were retorted by parents in questions 1 and 2 . These illustrated their concerns and to reveal their suggestions to school to change in order to enhance their children's experience in online learning. In fact, the most repeated suggestion for the two questions were the increase in the use of interactive videos between the teachers and the students as teachers' interaction, availability, cooperation, and flexibility, teachers' feedback, teachers' positive attitudes in online learning, and teaching positive reinforcement and motivation in online learning throughout visual interactive videos are considered the main motivating factors in online learning [39]. Hence, although parents confirmed throughout the quantitative statistical analysis of their answers that they are satisfied with the teachers' attitudes, their flexibility and cooperation in online learning $(70 \%)$, only $57 \%$ of the participants agreed that their children are receiving personalized, valid and constructive feedback in online learning. Thus, the suggestion was made for more interactive live sessions where teachers can meet the students on a one-to-one basis to provide the apprentice with valid feedback, to answer her/his questions, to explain any misunderstood concept and to positively reinforce her/him in online learning in order to enhance her/his learning and academic achievement. This suggestion is consistent with both the literature review and online education theories/models that assert the efficiency of the teachers' positive reinforcement, comments and feedback to the students' academic work [40, 41].

\section{CONCLUSION}

To the best of our knowledge, this is the first study that addresses the parents' views of online learning during the COVID-19 pandemic in the UAE context. Numerous conclusions are drawn from the findings. In fact, primary quantitative and qualitative data revealed that parents had equally different levels of satisfaction fluctuating from satisfied to dissatisfy and neither satisfied or dissatisfied with online learning in the UAE context. Fathers along with non-working parents were the least satisfied with the online learning while parents of elementary schoolers were the most satisfied; school-parent communication is mandatory to address parents' concerns with online learning; daily interactive live sessions between teachers and students 
are highly required to engage the children and maintain their interest in online learning; teachers are asked to positively reinforce the students and to give them personalized constructive feedback to enhance their academic achievement in online learning; and lastly, schools are asked to reconsider the online material load, the tuition fees, the assessment procedure and the lengthy-time of online learning.

\section{RECOMMENDATIONS}

This research provided a wider understanding of the parents' views of online learning during the COVID-19 pandemic in the UAE context as well as it revealed the parents' suggestions to schools for better online learning quality. It is highly recommended that educational stakeholders take into consideration the parents' suggestions to meet the students' educational and emotional needs in online learning as well as to satisfy the parents.

However, this study did not intend to compare the parents' views and satisfaction in the different 7 Emirates, neither to compare the parents' views of online learning in public and private sectors. Thus, it is highly recommended to carry detailed research in each and every Emirate in order to highlight the difference in the efficiency of online learning between the 7 Emirates. Moreover, it will be interesting to conduct studies within each Emirate to compare the parents' views and satisfaction of online learning between public and private schools. Furthermore, findings revealed that mothers were more satisfied than fathers of online learning. It will be interesting to investigate the reasons behind this finding as well as to carry out detailed research to find out why working parents were more satisfied of online learning than non-working parents in the UAE context. Finally, parents' answers to the unstructured questions in the qualitative part of the study were mainly brief phrases and rarely articulated in ample sentences. Therefore, the meaning of few answers came ambiguous and indefinite without supplementary elaboration. Forthcoming studies should amass wealthier and deeper qualitative data using substitute methods such as focus groups and interviews in order to gain a profound understanding of the parents' views of online learning during the COVID-19 pandemic in the UAE context.

\section{REFERENCES}

1. Fauci. (2020). "Dr. Anthony Fauci says coronavirus turned 'out to be my worst nightmare' and it 'isn't over'. CNBC [online]. [Accessed 10 June 2020]. Please, provide the online link.

2. WHO. (2020). "A message of solidarity on Covid19". WHO [online]. [Accessed 16 June 2020].

3. Duffin. (2020). Impact of the coronavirus pandemic on the global economy - Statistics \& Facts. STATISTA. [Accessed 9 June 2020].

4. Li \& Lalani. (2020). The COVID-19 pandemic has changed education forever. This is how. WORLD
ECONOMIC FORUM [online]. [Accessed 10 June 2020].

5. UNICEF. (2020). Coronavirus (COVID-19) guide for parents. [Accessed 15 June 2020].

6. Adek's parent guide for distance learning. (2020). UAE: ADEK. [Accessed 16 June 2020].

7. Rizvi. (2020). Coronavirus: UAE schools plan for e-learning to continue into 2021. The National. [Accessed 6 June 2020].

8. Huang, C., Wang, Y., Li, X., Ren, L., Zhao, J., Hu, Y., \& Cheng, Z. (2020). Clinical features of patients infected with 2019 novel coronavirus in Wuhan, China. The lancet, 395(10223), 497-506.

9. Abdallah, A. K. (2018). Parent's perception of elearning in Abu Dhabi schools in United Arab Emirates. International E-Journal of Advances in Social Sciences, 10, 30-41.

10. Hoi, S. C., Sahoo, D., Lu, J., \& Zhao, P. (2018). Online learning: A comprehensive survey.

11. Alenezi, A. (2020). The Role of e-Learning Materials in Enhancing Teaching and Learning Behaviors. International Journal of Information and Education Technology, 10(1).

12. Hung, M. L. (2016). Teacher readiness for online learning: Scale development and teacher perceptions. Computers \& Education, 94,120-133.

13. Xhaferi, G., Farizi, A., \& Bahiti, R. (2018). Teachers' attitudes towards e-learning in higher education in Macedonia Case study: University of Tetovo. European Journal of Electrical Engineering and Computer Science, 2(5).

14. Hartnett, M. (2016). The importance of motivation in online learning. Motivation in online education, 5-32.

15. Moody, A. K., \& Swafford, J. (2019). Practical strategies for e-book use in early childhood classrooms (K-5). In Reading in the digital age: Young children's experiences with e-books (pp. 217-233). Springer, Cham.

16. Crommelinck, M., \& Anseel, F. (2013). Understanding and encouraging feedback- seeking behaviour: a literature review. Medical education, 47(3), 232-241.

17. Arkorful, V., \& Abaidoo, N. (2015). The role of elearning, advantages and disadvantages of its adoption in higher education. International Journal of Instructional Technology and Distance Learning, 12(1), 29-42.

18. Rowe, F. A., \& Rafferty, J. A. (2013). Instructional design interventions for supporting self-regulated learning: enhancing academic outcomes in postsecondary e-learning environments. Journal of Online Learning and Teaching, 9(4), 590-601.

19. Gestwicki, C. (2015). Home, school, and community relations. Cengage Learning.

20. Patte, M. M. (2003). Defining parent involvement in rural elementary school through the eyes of parents, students, teachers, and administration: A case study. 
21. Epstein, J. L., Sanders, M. G., Sheldon, S. B., Simon, B. S., Salinas, K. C., Jansorn, N. R., ... \& Hutchins, D. J. (2018). School, family, and community partnerships: Your handbook for action. Corwin Press.

22. Wirt, J., Choy, S., Rooney, P., Provasnik, S., Sen, A., \& Tobin, R. (2004). The Condition of Education 2004. NCES 2004-077. US Department of Education.

23. Domina, T. (2005). Leveling the home advantage: Assessing the effectiveness of parental involvement in elementary school. Sociology of education, 78(3), 233-249.

24. Al Sumaiti, R. (2012). Parental involvement in the education of their children in Dubai. Dubai School of Government Policy Brief, 30, 1-8.

25. KHDA. (2011a). DSIB Inspection Handbook 20112012. Knowledge and Human Development Authority, Dubai.

26. Fraenkel, J. R., \& Wallen, N. E. (2009). The nature of qualitative research. How to design and evaluate research in education, seventh edition. Boston: McGraw-Hill, 420.

27. KHDA. (2012). In Search of Good Education Volume 2, 2012; The facts behind Emiratis in private schools in Dubai. 2nd edn. KHDA. Viewed 16 June 2020.

28. Creswell, J. W., \& Clark, V. L. P. (2017). Designing and conducting mixed methods research. Sage publications.

29. Bullen, C. K., Laird, G. M., Durand, C. M., Siliciano, J. D., \& Siliciano, R. F. (2014). New ex vivo approaches distinguish effective and ineffective single agents for reversing HIV-1 latency in vivo. Nature medicine, 20(4), 425-429.

30. Grbich, C. (2007). An introduction: Qualitative data analysis. London, UK: Sage. Grootenhuis, MA, \& Last, BF (1997). Predictors of parental emotional adjustment to childhood cancer. PsychoOncology, 6(2), 115-128.
31. Sandelowski, M. (2010). What's in a name? Qualitative description revisited. Research in nursing \& health, 33(1),pp. 77-84.

32. Elo, S., \& Kyngäs, H. (2008). The qualitative content analysis process. Journal of advanced nursing, 62(1), 107-115.

33. Sandelowski, M., \& Leeman, J. (2012). Writing usable qualitative health research findings. Qualitative health research, 22(10), pp.1404-1413.

34. Braun, V., \& Clarke, V. (2006). Using thematic analysis in psychology. Qualitative research in psychology, 3(2), pp. 77-101.

35. Wimmer, D. R., \& Dominick, R. J. (2011). Qualitative research methods. Mass media research: An introduction, 9,114-154.

36. Goldsteen, R. L., Goldsteen, K., \& Dwelle, T. (2014). Introduction to public health: promises and practice. Springer Publishing Company.

37. Kong, S. C. (2018). Parents' perceptions of elearning in school education: Implications for the partnership between schools and parents. Technology, Pedagogy and Education, 27(1), 15-31.

38. Stair, R., \& Reynolds, G. (2015). Fundamentals of information systems. Cengage Learning.

39. Karimi, M. N., \& Hosseini Zade, S. S. (2019). Teachers' use of motivational strategies: effects of a motivation-oriented professional development course. Innovation in Language Learning and Teaching, 13(2), pp.194-204.

40. Dahod, A. M., Silva, M., Higgins, P., Ghai, R., DePietro, J., Lopez, N., \& Shieh, P. (2008). U.S. Patent No. 7,372,826. Washington, DC: U.S. Patent and Trademark Office.

41. Murphy, E., \& Rodríguez-Manzanares, M. A. (2009). Teachers' perspectives on motivation in high-school distance education. 